\title{
PENGARUH LEVERAGE, UKURAN PERUSAHAAN, DAN LIKUIDITAS TERHADAP KEPUTUSAN HEDGINGPADA PERUSAHAAN MANUFAKTUR TERDAFTAR DI BEI
}

\author{
I Gusti Made Diah Windari ${ }^{1}$ \\ Ni Ketut Purnawati ${ }^{2}$ \\ ${ }^{1,2}$ Fakultas Ekonomi dan Bisnis Universitas Udayana (Unud), Bali, Indonesia \\ e-mail:diahwindari1315@gmail.com
}

\begin{abstract}
ABSTRAK
Tujuan penelitian ini adalah untuk mengetahui signifikansi pengaruh leverage, ukuran perusahaandan likuiditas terhadap keputusan hedging. Penelitian ini dilakukan pada perusahaan manufaktur yang terdaftar pada Bursa Efek Indonesia periode 2016-2017. Jumlah sampel 124 perusahaan manufaktur dengan menggunakan teknik sampling sensus. Pengumpulan data dilakukan dengan metode observasi non partisipan yaitu melalui data laporan keuangan yang dipublikasikan pada website www.idx.co.id. Teknik analisis yang digunakan dalam penelitian ini adalah analisis regresi logistik. Hasil pengujian hipotesis menunjukan bahwa variabel leverage yang diproksikan dengan debt to equity ratio memiliki pengaruh positif dan signifikan terhadap keputusan hedging. Variabel ukuran perusahaanmemiliki pengaruh positif dan signifikan terhadap keputusan hedging. Likuiditas yang diproksikan dengan current ratio menunjukan pengaruh yang negatif dan signifikan terhadap keputusan hedging.
\end{abstract}

Kata Kunci: leverage, ukuran perusahaan, likuiditas, hedging

\begin{abstract}
The purpose of this study is to determine the significance of the influence of leverage, firm size and liquidity on hedging decisions. This research was conducted at manufacturing companies listed on the Indonesia Stock Exchange for the period 2016-2017. The number of samples is 124 manufacturing companies using census sampling techniques. Data collection is done by non-participant observation method, namely through financial report data published on the website www.idx.co.id. The analysis technique used in this study is logistic regression analysis. The results of hypothesis testing show that the leverage variable that is proxied by the debt to equity ratio has a positive and significant influence on hedging decisions. The variable size of the firm has a positive and significant influence on hedging decisions. Liquidity proxied by the current ratio shows a negative and significant effect on hedging decisions.

Keywords: leverage, firm size, liquidity, hedging
\end{abstract}




\section{PENDAHULUAN}

Dewasa ini, perkembangan perdagangan internasional sangat pesat. Hal tersebut dapat terlihat dari semakin seringnya pelaku bisnis untuk melakukan transaksi bisnis tidak hanya di negara asalnya melainkan merambah ke negaranegara lainnya. Setiap negara memiliki kemampuan yang berbeda dalam penguasaanteknologi, penguasaan sumber daya serta adanya kebutuhan dan kelebihan barang dan jasa dalam negeri, hal inilah merupakan beberapa faktor yang dapat mengakibatkan terjadi perdagangan internasional(Irawan, 2014). Perdagangan internasional tentu memiliki risiko yang lebih besar dibandingkan dengan melakukan perdagangan di dalam negeri karena adanya perbedaan mata uang di setiap negara.

Risiko yang paling sering terjadi jika melakukan perdagangan internasional adalah risiko fluktuasi valuta asing, risiko suku bunga, dan risiko harga komoditas, yang dapat berpengaruh negatif terhadap arus kas, nilai perusahaan serta dapat mengancam kelangsungan hidup perusahaan (Saragih dan Musdholifah, 2017). Risiko terbesar dari transaksi perdagangan internasional yaitu fluktuasi valuta asing karena akan berdampak langsung pada omzet penjualan, penetapan harga produk, tingkat laba eksportir-importir serta adanya ketidakpastian nilai aset dan kewajiban. Perusahaan dalam melakukan perdagangan internasional tidak lepas dari penggunaan kurs valuta asing. Kurs valuta asing selalu mengalami fluktuasi dapat dilihat pada Gambar 1. 


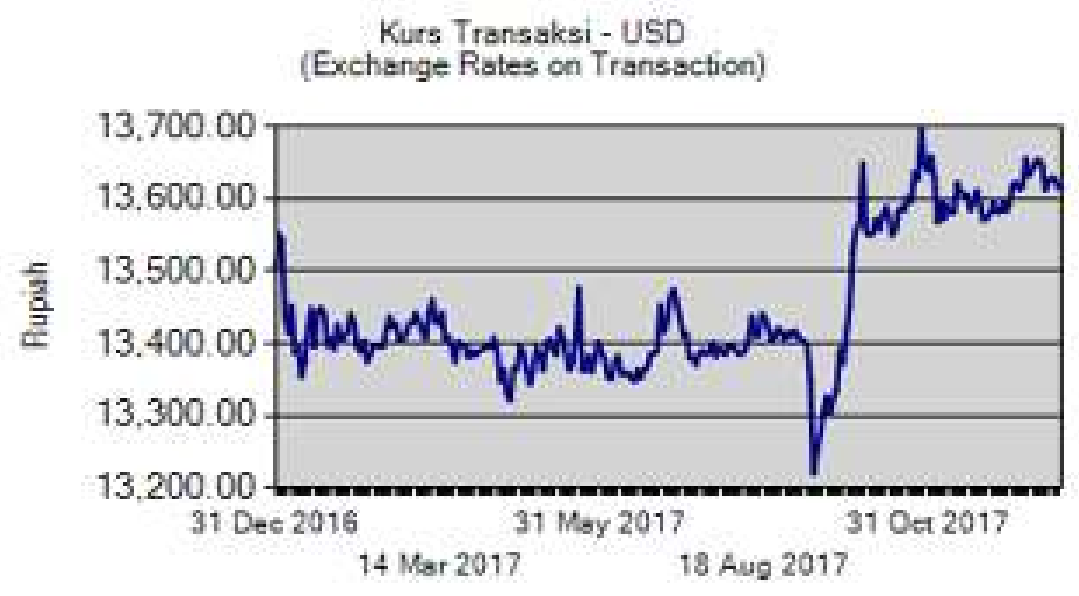

Gambar 1. Kurs Valuta Asing Dolar Amerika

Sumber :www.bi.go.id, 2018

Gambar 1. menunjukkan adanya fluktuasi kurs dollar (USD) terhadap rupiah (IDR) dari tahun 2016 hingga 2017. Grafik kurs transaksi USD di atas menunjukkan kurs transaksi USD terhadap IDR selama 2 tahun yaitu mulai tanggal 31 Desember 2016 hingga 31 Oktober 2017. Berdasarkan gambar di atas dapat dilihat bahwa pada tanggal 31 Desember 2016 kurs transaksi USD terhadap IDR yaitu sebesar Rp. 13.503 per 1.00 USD, lalu mengalami penguatan dimana pada tanggal 14 Maret 2017 kurs transaksi USD terhadap IDR mencapai pada angka Rp. 13.427 per 1.00 USD. Kurs transaksi USD terhadap IDR mengalami penguatan kembali pada tanggal 31 Mei 2017 sebesar Rp. 13.388 per 1.00 USD, namun pada tanggal 18 Agustus 2017 terjadi pelemahan mata uang yang menyentuh angka Rp 13.435 per 1.00 USD. Pada akhir Oktober yaitu tanggal 31 Oktober 2017 kembali terjadi pelemahan mata uang yang mencapai angka Rp. 13.640 per 1.00 USD. Data yang ditunjukkan mengartikan bahwa ketika suatu perusahaan ingin melakukan transaksi valuta asing akan mengalami risiko fluktuasi terhadap valuta asing. Jika IDR mengalami mengalami depresiasi atau 
I Gusti Made Diah Windari, Pengaruh Leverage,Ukuran...

jika mata uang USD mengalami apresiasi, maka harga impor barang akan lebih mahal sehingga berdampak pada kenaikan harga yang juga akan mengalami peningkatan (Mishkin, 2008:89). Hal ini dapat menyebabkan kerugian bagi perusahaan yang melakukan perdagangan internasional akibat adanya perbedaaan mata uang tiap negara, karena ketika mata uang lokal mengalami depresiasi maka perusahaan harus mengeluarkan lebih banyak mata uang lokal untuk transaksi tersebut.

Risiko memang tidak dapat langsung dihilangkan namun jika perusahaan tidak berani mengambil risiko maka perusahaan akan kehilangan kesempatan untuk mendapat keuntungan. Menurut Hanafi $(2012 ; 1)$ risiko didefinisikan sebagai kemungkinan hasil yang diperoleh menyimpang dari apa yang diharapkan. Alternatif untuk meminimalisir risiko yaitu dengan penambahan derivatif sebagai instrumen hedging dalam manajemen risiko.Hedgingdalam dunia keuangan digunakan sebagai suatu investasi yang dilakukan dengan tujuan untuk meminimalisir atau bahkan meniadakan risiko pada investasi lainnya (Dewi dan Purnawati, 2016).

Hedging dapat dilakukan dengan penggunaan instrumen derivatif.Instrumen derivatif adalah suatu kontrak perjanjian antara kedua belah pihak untuk memperjualbelikan sejumlah aset saat ini dengan harga yang sudah disepakati namun digunakan di masa mendatang dengan tanggal yang sudah ditetapkan pada kontrak tersebut (Dewi dan Purnawati, 2016).

Instrumen keuangan derivatif antara lain futures contracts, forward contract, options contract, dan swap contract.Kontak forward serupa dengan 
kontrak futures karena memungkinkan pembeli untuk mengunci harga yang harus dibayarkan bagi suatu valuta tertentu pada suatu waktu di masa depan, tetapi karakteristik kontrak futures berbeda dengan kontak forwarddimana kontrak futures dijual di bursa, sementara tiap kontrak forward diperoleh melalui negosiasi antara suatu bank komersil melalui jaringan telekomunikasi (Madura, 2006: 156).

Opsi merupakan suatu kontrak dimana penjual opsi menjamin adanya hak (bukan suatu kewajiban) dari pembeli opsi, untuk membeli atau menjual saham tertentu pada waktu dan harga yang telah ditetapkan.Instrumen keuangan derivatif yang terakhir yaitu swap.Karakteristik dari swap adalah tersedia dalam jangka waktu menengah dan jangka waktu panjang, mengandung risiko kredit namun tidak diperlukan transfer uang tunai di awal perjanjian, serta kontrak dapat dibuat berdasarkan kebutuhan pihak-pihak yang berkepentingan (Mitariani et al., 2013).

Pengambilan keputusan hedging dapat dipengaruhi oleh beberapa faktor yaitu leverage, ukuran perusahaan (firm size), dan likuiditas (Megawati et al., 2016). Leveragedalam dunia keuangan merupakan kemampuan perusahaan untuk memenuhi kewajiban finansialnya baik dalam jangka pendek maupun jangka panjang, atau mengukur sejauh mana perusahaan dibiayai dengan hutang (Wiagustini, 2013; 85). Leverage dapat diukur menggunakan debt to equity ratio (DER).

Hasil penelitian dari Eang et al. (2013) menyatakan bahwa leverage memiliki hubungan positif dan signifikan dengan penggunaan derivatif sebagai pengambilan keputusan hedging hasil ini didukung oleh penelitian yang dilakukan 
I Gusti Made Diah Windari, Pengaruh Leverage,Ukuran...

Nuzul dan Lautania (2015) yang mengemukakan hasil yang serupa.Penelitian bertentangan dikemukakan oleh Widyagoca dan Lestari (2016); Raghavendra dan Velmurugan (2014) yang menyatakanbahwa debt to equity ratio (DER) berpengaruh negatif dan signifikan terhadap penggunaan instrumen derivatif sebagai pengambilan keputusan hedging. Penelitian Afza dan Atia (2011) menyatakan leverage memiliki hubungan negatif dengan penggunaan derivatif dalam pengambilan keputusan hedging.

Faktor selanjutnya yaitu ukuran perusahaan. Ukuran suatu perusahaan berpengaruh terhadap pengambilan keputusan.Penelitian dari Shiu et al. (2012); Saragih dan Musdholifah (2017) menyatakan bahwa ukuran perusahaan memiliki pengaruh positif dan signifikan dalam penggunaan derivatif sebagai pengambilan keputusan hedging. Berbanding terbalik dengan penelitian dari Chen dan King (2014) menyatakan bahwa ukuran perusahaan berpengaruh negatif terhadap aktivitas hedging menggunakan instrumen derivatif pada suatu perusahaan.

Likuiditas merupakan kemampuan perusahaan untuk memenuhi kewajiban finansialnya dalam jangka pendek (Wiagustini, 2013; 85).Likuiditasdapat diukur dengan current ratio. Menurut penelitian terdahulu yang dilakukan oleh Widyagoca dan Lestari (2016), current ratio berpengaruh positif namun tidak signifikanterhadap keputusan hedging. Putro dan Chabachib (2012) mendapatkan hasil bahwa likuiditas dengan kebijakan hedging perusahaan memiliki pengaruh positif namun tidak signifikan.Penelitian dari Shaari et al. (2013) mengatakan bahwa current ratio memiliki hubungan negatif dan tidak signifikan dengan 
penggunaan derivatif. Chaudry (2014) menyatakan likuiditas berpengaruh negatif terhadap keputusan hedging dengan penggunaan instrumen derivatif.

Penelitian ini memfokuskan pada perusahaan manufaktur karena sebagian besar perusahaan sektor ini aktif dalam transaksi internasional seperti ekspor dan impor. Kementrian industri menyatakan pada tahun 2016 dan 2017, perusahaan manufaktur berkontribusi besar hingga lebih dari 70 persen dari total nilai ekspor dan nilai impor di Indonesia (www.kemenperin.go.id). Hal ini dapat dilihat dari Tabel 1 mengenai pertumbuhan ekspor dan impor yang dilakukan oleh sektor manufaktur dibanding dengan sektor lain dalam kurun waktu 2 tahun yaitu tahun $2016-2017$.

Tabel 1.

Pertumbuhan Ekspor dan Impor di Indonesia Tahun 2016 - 2017 (dalam Juta US\$)

\begin{tabular}{cccccc}
\hline \multirow{2}{*}{ No } & \multirow{2}{*}{ Sektor } & \multicolumn{2}{c}{ Ekspor } & \multicolumn{2}{c}{ Impor } \\
& & $\mathbf{2 0 1 6}$ & \multicolumn{1}{c}{$\mathbf{2 0 1 7}$} & $\mathbf{2 0 1 6}$ & $\mathbf{2 0 1 7}$ \\
\hline 1. & Sektor Manufaktur & $109.762,98$ & $125.023,30$ & $108.265,66$ & $122.151,62$ \\
2. & Sektor lainnya & $22.317,82$ & $28.060,6$ & $8.647,94$ & $10.517,88$ \\
Total & $132.080,8$ & $153.083,9$ & $116.913,6$ & $132.669,5$ \\
\multicolumn{2}{l}{ Sumber } & Kementrian Industri, 2017 & & &
\end{tabular}

Tabel 1. terlihat bahwa pertumbuhan ekspor dan impor di Indonesia pada tahun 2016 - 2017 didominasi oleh sektor manufaktur. Rata - rata kontribusi ekspor dari perusahaan manufaktur hingga tahun 2017 sebesar 82,3 persen sedangkan sektor lainnya seperti sektor pertambangan dan sektor pertanian sebesar 17,7 persen. Rata - rata kontribusi impor dari perusahaan manufaktur hingga tahun 2017 sebesar 78,2 persen sedangkan sektor lainnya sebesar 21,8 persen. Pesatnya perusahaan manufaktur dalam melakukan ekspor dan impor inilah yang membuat perusahaan rentan akan terkena dampak dari risiko fluktuasi nilai tukar yang dapat meningkatkan risiko kerugian bagi perusahaan. 
I Gusti Made Diah Windari, Pengaruh Leverage,Ukuran...

Leverage mengukur sejauh mana perusahaan menggunakan pendanaan melalui utang.Semakin banyak suatu perusahaan menggunakan utang (high leverage) dalam bentuk valuta asing pada struktur modalnya maka cenderung perusahaan melakukan hedging, karena perusahaan dengan leverage ratioyang lebih tinggi memungkinkan perusahaan menghadapi risiko kesulitan keuangan (Jiwandhana dan Triaryati, 2016).Hedgingdilakukan sebagai upaya perusahaan untuk melindungi arus kas internal perusahaan selama operasi dan perusahaan mampu mengurangi biaya dari kesulitan keuangan (Shaari et al.,2013). Suatu perusahaan membutuhkan modal dalam bentuk hutang ataupun ekuitas, apabila perusahaan ingin tumbuh.

Kelebihan dari penggunaan utang berbentuk valuta asing adalah bunga yang ditawarkan lebih rendah dibanding dengan pinjaman dalam bentuk rupiah, sementara kelemahannya yaitu risiko valuta asing yang akan ditanggung perusahaan akan besar karena jika kurs valuta asing mengalami apresiasi terhadap kurs valuta lokal maka utang valuta asing tersebut akan menekan, bahkan menghilangkan margin keuntungan perusahaan. Berkurangnya keuntungan ini terjadi karena perusahaan akan membutuhkan lebih banyak valuta lokal untuk melunasi utang valuta asing tersebut. Semakin besar risiko fluktuasi valuta asing yang ditanggung suatu perusahaan akibat penggunaan utang dalam bentuk valuta asing maka semakin diperlukannya hedging dalam meminimalisir risiko tersebut. Hal ini sesuai dengan penelitian yang dilakukan oleh Eang et al. (2013); Nuzul dan Lautania (2015); Söhnke, et al. (2009); Klingeberg et al. (2017), Yong et al. 
(2014); Lantara (2012) serta Lantara dan Takao (2012). Berdasarkan paparan yang telah dijelaskan, maka hipotesis penelitian ini:

$\mathrm{H}_{1}$ : Leverage berpengaruh positif dan signifikan terhadap keputusan hedging

Ukuran perusahaan adalah tingkat besar kecilnya perusahaan yang dilihat dari nilai total aset dari perusahaan. Semakin besar ukuran suatu perusahaan maka akan semakin besar aktivitas yang terjadi pada perusahaan tersebut, dan semakin tinggi pula risiko yang ditanggung perusahaan karena semakin luasnya perdagangan yang dilakukan perusahaan. Ukuran perusahaan yang besar pada umumnya melakukan perdagangan sampai ke luar negeri, dengan begitu perusahaan tersebut berpeluang terdampak risiko fluktuasi kurs valuta asing, sehingga memungkinkan perusahaan akan melakukan hedging.

Pernyataan ini diperkuat dari hasil penelitian terdahulu yang dilakukan oleh Shiu et al. (2012); Saragih dan Musdholifah (2017); Rashid (2010); Megawati (2016); Nguyen dan Faff (2002); Guniarti (2014) serta Raghavendra (2014) yang menyatakan bahwa ukuran perusahaan memiliki pengaruh positif dan signifikan dalam penggunaan derivatif sebagai pengambilan keputusan hedging. Berdasarkan uraian yang telah dijelaskan, maka hipotesis penelitian ini:

$\mathrm{H}_{2}$ : Ukuran perusahaan berpengaruh positif dan signifikan terhadap keputusan hedging.

Likuiditas digunakan oleh perusahaan maupun investor untuk mengetahui tingkat kemampuan perusahaan dalam memenuhi kewajiban jangka pendeknya. Kemampuan perusahaan dalam memenuhi kewajiban jangka pendeknya akan semakin berat ketika terdapat utangjangka pendek dalam bentuk mata uang asing. Nilai utang akan mengalami fluktuasi seiring dengan pergerakan nilai tukar mata 
uang lokal terhadap mata uang asing. Jika mata uang lokal mengalami pelemahan maka nilai utang akan meningkat, keadaan inilah akan menimbulkan risiko yang lebih besar.

Semakin likuid suatu perusahaan maka semakin kecil risiko kegagalan perusahaan dalam memenuhi kewajiban jangka pendeknya sehingga ancaman kesulitan keuangan juga kecil yang akan berdampak pada menurunnya aktivitas hedging yang dilakukan perusahaan. Likuiditas berpengaruh negatif dan signifikan terhadap keputusan hedging. Pernyataan ini sesuai dengan hasil penelitian terdahulu yang dilakukan oleh Shaari et al.(2013), Megawati, et al. (2016), Chaudry (2014); Dewi dan Purnawati (2016); Klingeberg et al. (2017); Velasco (2014) yang menyatakan likuiditas berpengaruh negatif terhadap keputusan hedging. Berdasarkan penjelasan sebelumnya, maka hipotesis mengenai hubungan likuiditas terhadap keputusan hedging adalah:

$\mathrm{H}_{3}$ : Likuiditas berpengaruh negatif dan signifikan terhadap keputusan hedging.

\section{METODE PENELITIAN}

Ruang lingkup penelitian ini pada perusahaan manufaktur di Bursa Efek Indonesia (BEI) pada periode 2016-2017.Populasi dari penelitian ini adalah seluruh perusahaan manufaktur yang melakukan transaksi internasional seperti impor maupun ekspor pada periode 2016-2017 yaitu sebanyak 124 perusahaan. Teknik analisis data yang digunakan untuk memecahkan permasalahan yang terdapat dalam penelitian ini adalah teknik analisis Regresi Logistik dengan menggunakan Statistical Product and Service Solution (SPSS). Model analisis regresi logistik dapat dirumuskan sebagai berikut. 
$\ln \left(\frac{\rho}{1-\rho}\right)=\beta_{0}+\beta_{1} \cdot X_{1}+\beta_{2} \cdot X_{2}+\beta_{3} \cdot X_{3}+$

Keterangan :

$\begin{array}{ll}\ln \left(\frac{\rho}{1-\rho}\right) & : \text { Keputusan Hedging } \\ \beta_{0} & : \text { Konstanta } \\ \beta_{1-3} & : \text { Koefisien regresi } \\ \mathrm{X}_{1} & : \text { Leverage } \\ \mathrm{X}_{2} & : \text { Ukuran perusahaan } \\ \mathrm{X}_{3} & : \text { Likuiditas } \\ \mathrm{e} & : \text { Standard Error }\end{array}$

\section{HASIL DAN PEMBAHASAN}

Berdasarkan hasil olahan SPSS yang meliputi variabel independen yaitu leverage $\left(\mathrm{X}_{1}\right)$ yang diukur dengan menggunakan debt to equity ratio, ukuran perusahaan $\left(\mathrm{X}_{2}\right)$ yang diukur dengan menggunakan $\ln$ (total aset), dan likuiditas $\left(\mathrm{X}_{3}\right)$ yang diukur dengan menggunakan current ratio maka dapat diketahui nilai maksimum nilai minimum, nilai mean dan standar deviasi dari tiap variabel tersebut pada Tabel 2 .

Tabel 2.

Analisis Deskriptif Variabel Bebas

\begin{tabular}{lrrrrr}
\hline & N & Minimum & Maximum & \multicolumn{1}{c}{ Mean } & Std. Deviation \\
\hline DER & 248 & 0,08 & 85,87 & 1,5425 & 5,58280 \\
SIZE & 248 & 11,82 & 19,50 & 14,7869 & 1,53381 \\
CR & 248 & 22,87 & 1039,62 & 224,9316 & 170,56957 \\
Valid N (listwise) & 248 & & & & \\
Sumber: Data diolah, 2018 & & & & &
\end{tabular}

Tabel 2. dapat dilihat bahwa nilai terendah dari variabel DER adalah sebesar 0,08 yang terdapat pada perusahaan Industri Jamu dan Farmasi Sido Muncul Tbk tahun 2016 sedangkan nilai tertinggi dari variabel DER adalah sebesar 85,87 yang terdapat pada perusahaan Centex Tbk tahun 2017. Hal ini menunjukan bahwa besarnya variabel DER berkisar antara 0,08 sampai 85,87. Rata - rata 
penyimpangan nilai variabel DER sebesar 5,58280 dengan nilai rata-rata (mean) sebesar 1,5425. Standar deviasi yang tinggi menunjukan nilai DER pada perusahaan manufaktur sangat berfluktuasi.

Nilai terendah ukuran perusahaan sebesar 11,82 yang terdapat pada Alaska Industrindo Tbk tahun 2016 sedangkan nilai tertinggi dari variabel size sebesar 19,50 yang terdapat pada PT. Astra International Tbk tahun 2017. Hal ini menunjukan bahwa besarnya variabel size berkisar antara 11,82 sampai 19,50. Rata - rata penyimpangan nilai variabel size sebesar 1,53381 dari nilai rataratanya (mean) yaitu sebesar14,7869.

Nilai terendah dari variabel CR adalah sebesar 22,87 yang terdapat pada Panasia Indo Resources Tbk tahun 2017 sedangkan nilai tertinggi dari variabel CR adalah sebesar 1039,62yang terdapat pada Jaya Pari Steel Tbk tahun 2016. Hal ini menunjukan bahwa besarnya variabel CR berkisar antara 22,87 sampai 1039,62. Rata - rata penyimpangan nilai variabel CRsebesar 170,56957 dari nilai rata-ratanya (mean) yaitu sebesar 224,9316. Sampel dengan variabel hedging (Y) dapat dilihat pada Tabel 3.

Tabel 3.

Frekuensi Variabel Terikat

\begin{tabular}{lccccc}
\hline & & Frequency & Percent & Valid Percent & $\begin{array}{c}\text { Cumulative } \\
\text { Percent }\end{array}$ \\
\hline Valid & 0 & 148 & 59,7 & 59,7 & 59,7 \\
& 1 & 100 & 40,3 & 40,3 & 100,0 \\
& Total & 248 & 100,0 & 100,0 & \\
\hline
\end{tabular}

Sumber: Data diolah, 2018

Perusahaan manufaktur yang melakukan aktivitas hedging diberi kode 1 sedangkan untuk perusahaan manufaktur yang tidak melakukan hedging diberi kode 0 . Menurut Tabel 3 dapat dilihat bahwa terdapat aktivitas hedging yang 
dilakukan oleh perusahaan manufaktur sebanyak 100kali dan persentase sebesar 40,3\% sedangkan terdapat 148 kali aktivitas perusahaan dengan kategori tidak menggunakan hedging dan persentase sebesar 59,7\%.

Uji kelayakan model regresi dinilai dengan melihat tabel Hosmer and Lemeshow Test pada SPSS. Tabel Hosmer and Lemeshow Test menguji hipotesis nol bahwa data empiris sesuai dengan model. Hasil uji kelayakan model dapat dilihat pada tabel Hosmer and Lemeshow Test pada Tabel 4 sebagai berikut.

Tabel 4.

Hosmer and Lemeshow Test

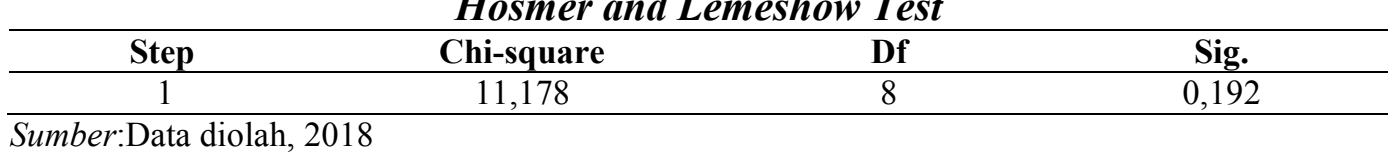

Model regresi pada penelitian ini menunjukkan nilai statistik Hosmer and LemeshowTest sebesar 11,178 dengan probabilitas signifikansi sebesar 0,192. Nilai siginifikansi menunjukkan yang lebih besar dari 5\% ini menunjukan bahwa model dalam penelitian ini dapat diterima karena cocok dengan data observasi dan dapat menjelaskan hubungan variabel independen dan variabel dependennya.

Keseluruhan model dapat dinilai dengan membandingkan nilai antara $-2 \log$ likehood pada awal (block number $=0$ ) dengan nilai -2 Log likehood pada akhir (block number=1). Nilai -2 Log Likehood dikatakan dapat menunjukan data model regresi yang baik apabila nilai dari -2 Log Likehood (block number $=0)>$ nilai -2 Log Likehood (block number=1).

Pada Tabel 5 dan Tabel 6 yang digunakan untuk menilai keseluruhan model dapat dilakukan dengan membandingkan nilai -2 Log Likehood (block number $=0$ ) dengan -2 Log Likehood (block number=1). Nilai pada -2 Log Likehood (block number $=0$ ) adalah sebesar 334,452 dan setelah dimasukkan tiga variabel 
I Gusti Made Diah Windari, Pengaruh Leverage,Ukuran...

independen nilai -2 Log Likehood pada akhir mengalami penurunan menjadi 312,892. Penurunan yang terjadi pada nilai -2 Log Likehood menunjukkan model regresi yang baik atau dengan kata lain model yang dihipotesiskan cocok dengan data.

Tabel 5.

Iteration History ${ }^{\text {a.b.c.d }}$ Block Number $=0$

\begin{tabular}{cccc}
\hline & & & Coefficients \\
Iteration & & $\mathbf{- 2}$ Log likelihood & $-0,387$ \\
Step 0 & 1 & 334,453 & $-0,392$ \\
& 2 & 334,452 & $-0,392$ \\
\hline
\end{tabular}

Sumber: Data diolah, 2018

Tabel 6.

Iteration History ${ }^{\mathrm{a}, \mathrm{b}, \mathrm{c}, \mathrm{d}}$ Block Number $=1$

\begin{tabular}{ccccccc}
\hline \multirow{2}{*}{ Iteration } & & & \multicolumn{4}{c}{ Coefficients } \\
\hline Step 1 & 1 & 313,198 & $-13,215$ & $-0,010$ & 5,186 & $-0,212$ \\
& 2 & 312,893 & $-14,477$ & $-0,015$ & 5,734 & $-0,258$ \\
& 3 & 312,892 & $-14,503$ & $-0,016$ & 5,748 & $-0,216$ \\
& 4 & 312,892 & $-14,503$ & $-0,016$ & 5,748 & $-0,216$ \\
\hline
\end{tabular}

Sumber: Data diolah, 2018

Model regresi yang baik adalah dengan tidak adanya gejala korelasi yang kuat antara variabel bebasnya. Pengujian multikolinearitas dalam regresi logistik menggunakan matrik untuk melihat besarnya korelasi antara variabel bebas. Apabila nilai matrik korelasi lebih kecil dari 0,8 memiliki arti tidak terdapat gejala multikolinearitas yang serius antar variabel bebas tersebut. Tabel 7 menunjukkan matriks korelasi antar variabel bebas.

Tabel 7.

Correlation Matrix

\begin{tabular}{cccccc}
\hline & & Constant & $\mathbf{X}_{\mathbf{1}}$ & $\mathbf{X}_{\mathbf{2}}$ & $\mathbf{X}_{\mathbf{3}}$ \\
\hline Step 1 & Constant & 1,000 & $-0,167$ & $-0,959$ & $-0,373$ \\
& $\mathrm{X}_{1}$ & $-0,167$ & 1,000 & 0,085 & 0,273 \\
& $\mathrm{X}_{2}$ & $-0,959$ & 0,085 & 1,000 & 0,099 \\
& $\mathrm{X}_{3}$ & $-0,373$ & 0,273 & 0,099 & 1,000 \\
\hline
\end{tabular}

Sumber:Data diolah, 2018 
Tabel 7. menunjukkan tidak ada nilai koefisien antar variabel bebas yang nilainya lebih besar dari 0,8 sehingga dapat disimpulkan bahwa tidak terdapat gejala multikolinearitas yang serius antar variabel bebas.

Kekuatan prediksi dari model regresi untuk memprediksi kemungkinan terjadi atau tidaknya aktivitas hedging dinyatakan dalam persen.Matrik klasifikasi ditampilkan pada Tabel 8 .

Tabel 8.

Classification Table ${ }^{\mathrm{a}}$

\begin{tabular}{cccccc}
\hline & & & Predicted & \\
Observed & & 0 & Hedging & & Percentage Correct \\
\hline Step 1 Hedging & 0 & 121 & 27 & 81,8 \\
& 1 & 64 & 36 & 36,0 \\
Overall Percentage & & & 63,3 \\
\hline
\end{tabular}

Sumber:Data diolah, 2018

Pada baris pertama Tabel 8. terlihat jumlah sampel yang tidak melakukan aktivitas hedging sebanyak $148(121+27)$. Model regresi dalam penelitian ini menunjukkan adanya pengurangan sejumlah sampel 27 sehingga total sampel yang tidak melakukan aktivitas hedging adalah sebanyak 121. Ketepatan klasifikasi pada model ini untuk memprediksi kemungkinan perusahaan tidak melakukan aktivitas hedging sebesar $81,8 \%$.

Baris kedua menunjukkan bahwa terdapat 100 sampel $(64+36)$ yang melakukan aktivitas hedging. Model ini memprediksi adanya pengurangan sejumlah 36 sampel sehingga total sampel yang diperdiksi melakukan hedgingsebanyak 64 sampel. Ketepatan klasifikasi pada model ini untuk memprediksi kemungkinan perusahaan melakukan hedging sebesar 36\%. Secara keseluruhan, ketepatan klasifikasi pada model regresi ini adalah adalah 63,3\%. 
Hubungan variabel independen terhadap variabel dependen dapat dilihat dari nilai Nagelkerke $R$ Square. Hasil uji koefisien determinasi ditunjukan pada Tabel 9.

Tabel 9.

Model Summary

\begin{tabular}{cccc}
\hline Step & $\mathbf{- 2} \mathbf{L o g}$ likelihood & Cox \& Snell R Square & Nagelkerke R Square \\
\hline 1 & $312,892^{\mathrm{a}}$ & 0,583 & 0,612 \\
\hline Sumber $:$ Data diolah, 2018 & &
\end{tabular}

Tabel 9. menunjukkan nilai Nagelkerke $R$ Square sebesar 0,612. Nilai tersebut berarti bahwa variasi dari variabel DER, Size dan CR (variabel independen) mampu menjelaskan variasi dari hedging (variabel dependen) sebesar $61,2 \%$ sedangkan $38,8 \%$ dijelaskan oleh variasi variabel lain yang tidak dimasukkan dalam model persamaan regresi.

Model regresi logistik dapat dibentuk dengan cara melihat pada nilai estimasi parameter dalam Variable in The Equation. Model regresi logistik yang terbentuk berdasarkan nilai estimasi parameter dalam Variable in The Equation ditampilkan pada Tabel 10.

Tabel 10.

\begin{tabular}{llrrrrc}
\multicolumn{7}{c}{ Variables in the Equation } \\
\hline & \multicolumn{7}{c}{ B } & S.E. & Wald & df & Sig. \\
\hline Step 1 & DER & 0,016 & 0.036 & 12,193 & 1 & 0,036 \\
& SIZE & 5,748 & 1,416 & 16,480 & 1 & 0,000 \\
& CR & $-0,261$ & 0,221 & 13,388 & 1 & 0,024 \\
& Constant & $-14,503$ & 4,103 & 12,492 & 1 & 0,000 \\
\hline
\end{tabular}

Sumber :Data diolah, 2018

Model regresi yang terbentuk berdasarkan nilai estimasi parameter dalam Variable in The Equation adalah sebagai berikut.

$$
\operatorname{Ln} \frac{p}{1-p}=-14,503+0,016 \mathrm{DER}+5,748 \mathrm{SIZE}-0,261 \mathrm{CR}
$$


Semakin besar nilai DER maka akan semakin besar probabilitas perusahaan mengambil keputusan hedging.Semakin besar ukuran suatu perusahaan akan semakin besar probabilitas perusahaan mengambil keputusan hedging.Semakin besar nilai CR maka akan semakin berkurang probabilitas perusahaan mengambil keputusan hedging.

Variabel debt to equity ratio (DER) yang merupakan proksi dari leverage menunjukkan nilai koefisien regresi sebesar 0,016 dengan pergerakan nilai probabilitas variabel sebesar 0,036 yang lebih kecil dari tingkat signifikansi 0,05 (5\%). Apabila nilai probabilitas signifikansi lebih kecil dari 0,05 dan nilai koefisien regresi menunjukkan hasil arah yang sama dengan hipotesis variabel leverage maka hal ini mengandung arti bahwa $\mathrm{H}_{0}$ ditolak.Hal ini mengandung arti bahwa variabel DER memiliki pengaruh yang positif dan signifikan terhadap keputusan hedging pada perusahaan manufaktur yang terdaftar di Bursa Efek Indonesia.Variabel ukuran perusahaan menunjukkan nilai koefisien regresi sebesar 5,748 dengan pergerakan nilai probabilitas variabel sebesar 0,000 yang lebih kecil dari tingkat signifikansi 0,05 (5\%). Hal ini mengandung arti bahwa $\mathrm{H}_{0}$ ditolak, maka variabel ukuran perusahaan memiliki pengaruh yang positif dan signifikan terhadap keputusan hedging pada perusahaan manufaktur yang terdaftar di Bursa Efek Indonesia.

Variabel Current Ratio (CR) yang merupakan proksi dari likuiditasmenunjukkan nilai koefisien regresi sebesar -0,261 dengan pergerakan nilai probabilitias variabel sebesar 0,024 yang lebih kecil dari tingkat signifikansi $0,05(5 \%)$. Hal ini mengandung arti bahwa $\mathrm{H}_{0}$ ditolak, maka variabel $\mathrm{CR}$ 
I Gusti Made Diah Windari, Pengaruh Leverage,Ukuran...

memiliki hubungan negatif signifikan terhadap keputusan hedging pada perusahaan manufaktur yang terdaftar di Bursa Efek Indonesia.

Uji parsial atau uji t merupakan uji yang digunakan untuk mengetahui pengaruh masing-masing variabel bebas terhadap variabel terikat secara parsial. Jika masing-masing koefisien signifikan dari variabel bebas memiliki nilai lebih kecil dari taraf signifikansi yaitu sebesar 5\% (0,05), maka dapat disimpulkan bahwa variabel bebas berpengaruh signifikan terhadap variabel terikat.

Tabel 11.

Variables in the Equation

\begin{tabular}{|c|c|c|c|c|c|c|}
\hline & & $\mathrm{B}$ & S.E. & Wald & $\mathrm{df}$ & Sig. \\
\hline \multirow[t]{4}{*}{ Step $1^{\mathrm{a}}$} & DER & 0,016 & 0.036 & 12,193 & 1 & 0,036 \\
\hline & SIZE & 5,748 & 1,416 & 16,480 & 1 & 0,000 \\
\hline & CR & $-0,261$ & 0,221 & 13,388 & 1 & 0,024 \\
\hline & Constant & $-14,503$ & 4,103 & 12,492 & 1 & 0,000 \\
\hline
\end{tabular}

Sumber :data diolah, 2018

Tabel 11. dapat dilihat bahwa nilai signifikansi dari masing masing variabel yaitu DER sebesar 0,036, Size sebesar 0,000 dan CR sebesar 0,024. Variabel DER dengan nilai signifikansi pada SPSS sebesar 0,036 $<0,05$ maka dari itu variabel DER berpengaruh signifikan terhadap keputusan hedging.

Variabel Size dengan nilai signifikansi pada SPSS sebesar $0,000<0,05$ maka dari itu variabel Size berpengaruh signifikan terhadap keputusan hedging. Variabel CR dengan nilai signifikansi pada SPSS $0,024<0,05$ maka dari itu variabel CR berpengaruh signifikan terhadap terhadap keputusan hedging.

Hasil uji regresi logistik menemukan bahwa debt to equity ratio sebagai proksi dari leverage memiliki pengaruh positif dan signifikan secara statistik terhadap variabel terikat yaitu keputusan hedging dengan menggunakan instrumen 
derivatif.Hasil ini menunjukkan bahwa hipotesis satu yang menyebutkan bahwa leverage berpengaruh positif dan signifikan terhadap keputusan hedging diterima.

Tingginya leverage mengindikasi bahwa perusahaan menggunakan lebih banyak utang daripada modal untuk menjalankan operasinya, oleh karena itu perusahaan harus lebih berhati - hati dalam menjalankan aktivitas operasi perusahaan terutama ketika melakukan transaksi internasional yang menggunakan valuta asing.Jika pendapatan perusahaan dalam bentuk mata uang lokal atau menjalankan operasi dalam mata uang lokal dan memiliki utang yang didenominasi valuta asing akan menghadapi eksposur valuta asing yang tinggi. Penguatan valuta asing terhadap mata uang lokal akan menyebabkan nilai utang dalam mata uang lokal meningkat, karena perusahaan harus mengeluarkan lebih banyak dana untuk membayar utangnya. Utang perusahaan akan memunculkan risiko ketika profit yang diperoleh lebih kecil dari biaya bunga yang harus dikeluarkan. Peningkatan nilai hutang ini dapat merugikan perusahaan dalam usaha pemenuhan kewajiban hutangnya maka perusahaan perlu melakukan tindakan hedging untuk mengurangi dampak buruk risiko tersebut pada perusahaan. Semakin tinggi leverage maka akan semakin besar tindakan hedging yang dilakukan untuk mengurangi dampak buruk risiko sehingga aktivitas hedging berhubungan positif dengan leverage.

Hasil penelitian sesuai dengan temuan Eang et al. (2013); Nuzul dan Lautania (2015); Söhnke, et al. (2009); Klingeberg et al. (2017), Yong et al. (2014); Lantara (2012) serta Lantara dan Takao (2012)menemukan bahwa leverageberpengaruh positif dan signifikan terhadap keputusan hedging.Hasil 
I Gusti Made Diah Windari, Pengaruh Leverage,Ukuran...

penelitian bertentangan dikemukakan oleh Widyagoca dan Lestari (2016); Raghavendra dan Velmurugan (2014); Afza dan Atia (2011)yang menyatakanhal sebaliknya.

Hasil uji regresi logistik menemukan bahwa $\ln ($ total aset) yang merupakan proksi dari ukuran perusahaan memiliki pengaruh positif dan signifikan secara statistik terhadap variabel terikat yaitu keputusan hedging dengan menggunakan instrumen derivatif. Hasil menunjukkan bahwa hipotesis dua yang menyebutkan bahwa ukuran perusahaanberpengaruh positif dan signifikan terhadap keputusan hedging dapat diterima.

Hasil penelitian menunjukkan nilai positif dan signifikan hal ini berarti bahwa semakin besar ukuran suatu perusahaan akan cenderung menggunakan hedging guna melindungi aset yang dimilikinya. Ukuran perusahaan yang besar tentunya memiliki aktivitas operasional perusahaan yang luas hingga merambat ke dunia internasional. Berbagai transaksi internasional yang dilakukan seperti ekspor, impor, pembelian bahan baku guna memperluas pangsa pasar dan meningkatkan produksi perusahaan tentunya akan menimbulkan risiko fluktuasi kurs valuta asing yang ditanggung perusahaan akibat dari transaksi internasional yang dilakukan sehingga akan meningkatkan perusahaan dalam menggunakan hedging guna meminimalisir risiko yang timbul akibat adanya fluktuasi kurs valuta asing.

Hasil ini sesuai dengan penelitian yang dilakukan oleh Shiu et al. (2012), Saragih dan Musdholifah (2017), Rashid (2010), Megawati, dkk. (2016), Nguyen dan Faff (2002), Guniarti (2014) serta Raghavendra (2014) yang melakukan 
penelitian tentang size dan menemukan hasil bahwa size berpengaruh positif dan signifikan terhadap keputusan hedging. Hasil yang bertentangan dikemukakan oleh Chen dan King (2014) yang menyatakan sebaliknya.

Hasil uji regresi logistik menemukan hasil bahwa current ratio sebagai proksi dari likuiditas berpengaruh negatif signifikan terhadap hedging. Berdasarkan hasil uji tersebut maka hipotesis ketiga yang menyatakan likuiditas berpengaruh negatif signifikan terhadap keputusan hedging diterima.

Tingginya likuiditas perusahaan mengindikasikan perusahaan mampu memenuhi kewajiban jangka pendeknya dan perusahaan memiliki dana cadangan untuk menghadapi risiko sehingga terhindar dari risiko kesulitan keuangan (financial distress). Perusahaan yang memiliki kewajiban jangka pendek dalam bentuk valuta asing akan rentan terkena dampak dari risiko fluktuasi valuta asing karena nilai utang akan mengalami fluktuasi seiring dengan pergerakan nilai tukar valuta lokal terhadap valuta asing. Jika valuta lokal mengalami pelemahan maka nilai utang akan meningkat, sehingga lebih banyakmata uang lokal yang harus dikeluarkan untuk membayar kewajiban jangka pendeknya yang dapat membebani perusahaan. Semakin likuid kondisi suatu perusahaan akan semakin rendah penerapan hedging karena kewajiban jangka pendeknya dapat terpenuhi, sehingga risiko gagal bayar dan kesulitan keuangan dapat dihindari.

Hasil yang didapat sesuai dengan penelitian Ameer (2010), Afza dan Atia (2011), Megawati dkk. (2016), Chaudry (2014), serta Dewi dan Purnawati (2016) yang mendapatkanhasil bahwa semakin tinggi rasio likuiditas maka penggunaan hedging akan semakin rendah.Hasil penelitian yang bertentangan dikemukakan 
I Gusti Made Diah Windari, Pengaruh Leverage,Ukuran...

oleh Widyagoca dan Lestari (2016) serta Putro dan Chabachib (2012) yang mendapatkan hasil sebaliknya.

\section{SIMPULAN}

Hasil penelitian menunjukan bahwa leverage memiliki pengaruh positif dan signifikan terhadap keputusan hedging dengan menggunakan instrumen derivatif. Hasil penelitian menunjukkan bahwa ukuran perusahaanmemiliki pengaruh positif dan signifikan terhadap keputusan hedging dengan menggunakan instrumen derivatif. Hasil penelitian menunjukkan bahwa likuiditas memiliki pengaruh negatif dan signifikan terhadap keputusan hedging dengan menggunakan instrumen derivatif.

Bagi perusahaan manufaktur yang memiliki tingkat hutang yang tinggi diharapkan menggunakan kebijakan hedging ketika melakukan transaksi internasional agar perusahaan mampu mengurangi beban hutang yang dimiliki dari risiko fluktuasi kurs valuta asing.Bagi perusahaan manufaktur dengan ukuran perusahaan besar yang aktif melakukan transaksi internasional diharapkan menggunakan kebijakan hedging agar perusahaan dapat menghindari risiko fluktuasi kurs valuta asing.Bagi perusahaan manufaktur yang memiliki tingkat likuiditas yang rendah diharapkan menggunakan kebijakan hedging agar dapat mempertahankan dana yang dimiliki sehingga tetap mampu memenuhi kewajiban jangka pendeknya.

Diharapkan untuk penelitian selanjutnya agar menggunakan variasi variabel lain yang mungkin berpengaruh terhadap aktivitas hedging untuk melihat pengaruhnya, seperti profitabilitas, kepemilikan manajerial, pajak, price earning 
ratio dan market to book value. Penelitian selanjutnya agar menggunakan periodehedging yang lebih tepat dan berbeda serta menggunakan sektor perusahaan yang berbeda pula sebagai sampel untuk lebih memperluas pengujian terhadap teori agar dapat melihat konsistensi pengaruh leverage, ukuran perusahaandan likuiditas terhadap keputusan hedging.

\section{REFERENSI}

Afza, Talat dan Alam Atia. (2011). Corporate derivatives and foreign exchange risk management: A case study of non-financial firms of Pakistan. The Journal of Risk Finance, Vol.12 (5):Pp 409-420.

Ariani, Ni Nengah Novi dan Gede Merta Sudiartha. (2017). Pengaruh Leverage, Profitabilitas, dan Likuiditas terhadap Keputusan Hedging Perusahaan Sektor Pertambangan di Bursa Efek Indonesia.E-Jurnal Universitas Udayana, Vol. 6 (1): Pp 347-374.

Bank Indonesia. (2018). Kurs Transaksi Bank Indonesia tahun 20162017.www.bi.go.id. Diakses pada 30 Oktober 2018.

Chaudhry, N. I., Mehmood, M. S., and Mehmood, A. (2014). Determinants of Corporate Hedging Policies and Derivative Usage in Risk Management Practices of Non-Financial Firms. Wulfenia Journal, Vol.21(7).

Chen, J., King and Tao-Hsien Dolly, (2014). Corporate Hedging and the Cost of Debt. Journal of Corporate Finance. Vol. 29: Pp 221-245.

Dewi, Ni Komang Reni dan Ni Ketut Purnawati. (2016). Pengaruh Market To Book Value Dan Likuiditas Terhadap Keputusan Hedging Pada Perusahaan Manufaktur Di BEI.E-Jurnal Manajemen Unud, Vol. 5(1): Pp $355-384$.

Eang, Kelvin Saw Lip; Ong Han Rong; Lim Mei Hui; Tan Wen Hui; dan Tung Ming Kiat. (2013). The Determinants of Derivative Usage In Malaysia Corporation. Final Year Project, UTAR.

Ghozali, Imam H.(2016). Aplikasi Analisis Multivariete dengan Program IBM SPSS23. Semarang: Universitas Diponegoro.

Guniarti, Fay. (2014). Faktor - Faktor Yang Mempengaruhi Aktivitas Hedging Dengan Instrumen Derivatif Valuta Asing.Jurnal Dinamika Manajemen. Vol.5(1): Pp.64-79. 
Hafidoh, Siti. (2017). Analisis Faktor-Faktor Yang Mempengaruhi Keputusan Hedging Pada Perusahaan Manufaktur Yang Terdaftar Di Bursa Efek Indonesia Tahun 2013-2015. Skripsi. Fakultas Ekonomi Dan Bisnis Universitas Bandar Lampung.

Hanafi, Mamduh. (2012). Manajemen Risiko,Edisi kedua. Yogyakarta: UPP STIM YKPN.

Hany, Ahmed; Alcino; Azevedo; Yilmaz, and Guney. (2014). "The Effect of Hedging on Firm Value and Performance: Evidence from the Nonfinancial UK Firms".

Irawan, B.P. (2014). Analisis Faktor Yang Mempengaruhi Aktivitas Instrumen Derivatif Valuta Asing Sebagai Pengambilan Keputusan Hedging (Studi Kasus Pada Perusahaan Manufaktur Yang Terdaftar Di BEI Periode 20092012). Skripsi. Fakultas Ekonomika dan Bisnis, Universitas Diponegoro.

Jiwandhana, RM Satwika Putra dan Nyoman Triaryati. (2016). Pengaruh Leverage dan Profitabilitas terhadap Keputusan Hedging Perusahaan Manufaktur Indonesia.E-Journal Manajemen Unud,Vol. 5(1): Pp 31-58.

Kementrian Industri. (2017). Laporan Ekspor dan Impor Industri Pengolahan tahun 2016-2017.www.kemenperin.com. Diakses pada 10 Desember 2018.

Klingeberg, JeromeGeyer; Hang, Markus; Rathgeber, Andreas W; Stöckl, Stefan; dan Walter, MatthiasAuthor Information. (2018). What do we really know about corporate hedging?.Business Research; Göttingen Vol. 11(1) : Pp 1-31.

Lantara, I Wayan Nuka. (2012).The Use of Derivatives as a Risk Management Instrumen: Evidence from Indonesian Non-Financial Firms. International Journal of Business and Economics; Taichung Vol. 11 (1) : Pp 45-62

Lantara, I Wayan Nuka and Atsushi Takao. (2012). The Determinants of the Use of Derivatives in the Japanese Insurance Companies. APJRI (Asian-Pacific Journal of Risk and Insurance); Vol 8 (1): Pp. 57-81.

Madura, Jeff. (2006). Manajemen Keuangan Internasional, Edisi Kedelapan. Jakarta. Erlangga.

Megawati, Ida Ayu Putu; Luh Putu Wiagustini dan Luh Gede Sri Artini. (2016). Determinasi Keputusan Hedging pada Perusahaan Manufaktur di Bursa Efek Indonesia.E-Jurnal Manajemen Universitas Udayana, Vol 7(10). 
Mitariani, Ni Wayan Eka. (2013). Analisis Perbandingan Penggunaan Hedging Antara Forward contract Dengan Currency Swap Untuk Meminimasi Risiko Foreign Exchange. Jurnal Managemen Strategi Bisnis Dan Kewirausahaan, Vol 7(1).

Mishkin, Frederic S. (2008). Ekonomi Uang, Perbankan, dan Pasar Keuangan (Edisi 8). Jakarta: Salemba Empat.

Nguyen Hoa, Faff Robert. (2002). On The Determinants of Derivative Usage by Australian Companies, Australian of Journal Management, 27(1), pp. 124.

Nuzul, N. dan M. F. Lautania. (2015). Pengaruh Leverage Financial Distress Dan Growth Options Terhadap Aktivitas Hedging Pada Perusahaan NonKeuangan Yang Terdaftar Di Bursa Efek Indonesia. JDAB 2(2): Pp 104113.

Putro, S Hardanto. (2012). Analisis Faktor yang Mempengaruhi Penggunaan Instrumen Derivatif Sebagai Pengambilan Keputusan Hedging (Studi kasus pada Perusahaan Automotive and Allied Products yang Terdaftar di BEI Periode 2006-2011).Skripsi pada Fakultas Ekonomi dan Bisnis Universitas Diponegoro: Yogyakarta.

Raghavendra, RH, dan Velmurugan PS. (2014). The Determinants of Currency Hedging in Indian IT Firms. Journal of Business \& Financial Affairs: Vol. $3(3)$.

Rashid, Ameer. (2010). "Determinant of Corporate Hedging Practices in Malaysia”.International Business Research. Vol. 3 (2) : Pp 120 -130.

Saragih, F., \& Musdholifah. (2017). Pengaruh Growth Opportunity, Firm Size, dan Liquidity Terhadap Keputusan Hedging Pada Perusahaan Perbankan Indonesa. Jurnal Ilmu Manajemen Vol. 5 (2): Pp 1-10

Shaari, Noor Azizah, Nurfadhilah Abu Hasan, Yamuna Rani Palanimally and Ramesh Kumar Moona Haji Mohamed. (2013). The Determinants of Derivative Usage : A Study on Malaysian Firms. Interdisciplinary Journal of Contemporary Research In Business. Vol.5 (2): Pp.300-316.

Shiu, Yung-MingWang, Chi- Feng; Adams, Andrew; Shin, dan Yi-Cheng. (2012).

On The Determinants Of Derivative Hedging By Insurance Companies:

Evidence From Taiwan. Asian Economic and Financial Review; Karachi Vol. 2(4) :Pp 538-552. 
Söhnke M. Bartram, Gregory W. Brown, dan Frank R. Fehle. (2009). International Evidence on Financial Derivatives Usage.Financial Management, Pp 185-206.

Spric, Danijela Milos dan Zeljko Sevic. (2012). Determinants of corporate hedging decision: Evidence from Croatian and Slovenian Companies. Research in International Business and Finance, 26(1): Pp 1-25.

Sugiyono. (2017). Metode Penelitian Bisnis : Pendekatan Kuantitatif, Kualitatif, Kombinasi dan R\&D. Bandung. Alfabeta.

Sulindawati, N.L. Gede; G. A. Yuniarta; dan I. G. A. Purnamawati. (2017). Manajemen Keuangan Sebagai Dasar Pengambilan Keputusan Bisnis. Jakarta. PT Rajagrafindo Persada.

Tandelilin, Eduardus. 2010. Portofolio dan Investasi Teori dan Aplikasi, Edisi Pertama. Kanisius IKAPI Yogyakarta.

Van Horne, James C. and John M. Wachowicz, Jr. (2012).Prinsip-prinsip Manajemen Keuangan. Edisi 13. Jakarta:Salemba Empat.

Velasco, Lawrence G. (2014).Factors Influencing Derivatives Usage by Selected Listed Companies in the Philippines. Philippine Management Review; Quezon City Vol. 21 Pp 1-12.

Wahyono, Teguh. (2009). 25 Model Analisis Statistik dengan SPSS 17. Jakarta. Elex Media Komputindo.

Wiagustini, Ni Luh Putu. (2013). Manajemen Keuangan. Udayana Press.

Widyagoca, I Gusti Putu Agung dan Putu Vivi Lestari. (2016). Pengaruh Leverage, Growth Opportunities, dan Liquidity terhadap Pengambilan Keputusan Hedging PT. Indosat Tbk. E-Jurnal Manajemen Unud.Vol. 5(2): Pp 1282-1308.

Yong, Hue Hwa Au; Robert Faff dan Keryn Chalmersa. (2014). Determinants of the extent of Asia-Pacific banks' derivative activities.Accounting and Management Information Systems Vol. 13 (3), Pp. 430-448. 